\title{
Análise termográfica da ação do jato de plasma no tratamento de rugas faciais - série de casos clínicos
}

\author{
Thermographic analysis of plasma jet action in the treatment of facial wrinkles - \\ serie of clinical cases
}

\begin{abstract}
Carla Barreto Silva de Cerqueira ${ }^{1}$, Mylana Almeida de Carvalho², Márcia Maria Peixoto Leite ${ }^{3}$, Alena Ribeiro Alves Peixoto Medrado ${ }^{*}$
${ }^{1}$ Acadêmica do Curso de Graduação em Fisioterapia da Universidade Federal da Bahia - UFBA; ${ }^{2}$ Fisioterapeuta Especialista em Dermatofuncional; ${ }^{3}$ Doutoranda do Programa de Pós-graduação em Processos Interativos de Órgãos e Sistemas da Universidade Federal da Bahia - UFBA; ${ }^{4}$ Professora Adjunto do Departamento de Biointeração do Instituto de Ciências da Saúde da Universidade Federal da Bahia - UFBA

\begin{abstract}
Resumo
Introdução: o processo de senescência do indivíduo ocorre de forma lenta e contínua e pode gerar inúmeras alterações, dentre elas o envelhecimento cutâneo, derivado do declínio das atividades celulares. Inúmeros recursos têm sido criados ao longo dos anos com a finalidade de frear e ou reverter os aspectos inestéticos da pele, ocasionados por esse processo. Um novo recurso terapêutico vem sendo usado com o objetivo de promover o rejuvenescimento através da diminuição de rugas e linhas de expressão, trata-se do Jato de plasma. Objetivo: avaliar o padrão de variação térmica do tecido tratado com jato de plasma, através da termografia infravermelha. Metodologia: trata-se de uma série de casos clínicos que envolveu 5 pacientes mulheres, com idade acima de 40 anos que apresentavam rugas faciais. As pacientes foram avaliadas e anestesiadas previamente. Em seguida, foi realizada a terapia com o jato de plasma, na região supraorbital. As pacientes foram avaliadas termograficamente antes e depois da anestesia e pósterapia. Resultado: constatou-se através da análise termográfica, uma significativa variação no coeficiente de temperatura da pele onde foi aplicado o anestésico e em seguida o jato de plasma $\left(\Delta \mathrm{T}>0,4^{\circ} \mathrm{C}\right)$, em todas as pacientes. Conclusão: o presente estudo comprovou através da utilização da termografia, que o jato de plasma foi capaz de gerar um aumento da temperatura local. Os autores sugerem que tal variação térmica pode ser resultante de um processo de vasodilatação na região tratada.

Palavras-chave: Termografia Infravermelha. Jato de Plasma. Rugas Faciais. Rejuvenescimento.
\end{abstract}

\begin{abstract}
Introduction: individual's senescence process takes place slowly and continuously beyond generates several changes including skin aging, since the decline in cellular activities. Countless resources have been created over the years, with the goal of stopping and / or reversing the unsightly aspects of the skin caused by this process. Thus, plasma jet, a new therapeutic resource has been used in order to promote rejuvenation through the reduction of wrinkles and expression lines. Objective: To evaluate the pattern of thermal variation of the tissue treated with a plasma jet, using infrared thermography. Methodology: this was a series of clinical cases involving 5 female patients over the age of 40 who had facial wrinkles. Patients were previously evaluated and anesthetized. Then, plasma jet therapy was performed in the supra-orbital region. Patients were evaluated for thermal imaging before and after anesthesia and post-therapy. Result: it was found through thermographic analysis, a significant variation in the temperature coefficient of the skin of all patients where the anesthetic and plasma jet were applied $\left(\Delta T>0.4^{\circ} \mathrm{C}\right)$. Conclusion: the present study proved through the use of thermography that the plasma jet was able to generate an increase in local temperature. The authors suggest that such thermal variation may be the result of a process of vasodilation in the treated region.

Keywords: Infrared Thermography. Plasma Jet. Facial Wrinkles. Rejuvenation.
\end{abstract}

\section{INTRODUÇÃO}

O processo de senescência do indivíduo ocorre de forma lenta e contínua. É capaz de gerar inúmeras alterações, dentre elas o envelhecimento cutâneo, derivado do declínio das atividades celulares. Promove uma redução na capacidade do organismo realizar, de maneira normal, as suas funções ${ }^{1,2}$. $O$ envelhecimento cutâneo é conside-

Correspondente/Corresponding: *Alena Ribeiro Alves Peixoto Medrado - Departamento de Biointeração, Instituto de Ciências da Saúde/UFBA - End: Av. Reitor Miguel Calmon, Vale do Canela- CEP:40231-300 Salvador/BA - Tel: (71) 993721250 -E-mail: alenamedrado@hotmail.com rado fisiológico. É resultante de processos intrínsecos, provenientes de alterações hormonais ou extrínsecos, devido à degeneração do DNA. O tabagismo, o consumo excessivo de álcool e a exposição aos raios ultravioleta são alguns dos agentes externos que podem ocasionar alterações no DNA ${ }^{3}$.

Um dos principais agentes externos capazes de acelerar o processo de envelhecimento cutâneo é a exposição, sem proteção, à radiação ultravioleta. Este processo pode ser denominado também de fotoenveIhecimento ${ }^{4}$. Os fibroblastos são células que participam ativamente da biossíntese do colágeno e da elastina, 
que conferem firmeza ao tecido cutâneo. A absorção dos raios ultravioletas pelas camadas mais profundas da pele, ou seja, pela derme, ocasiona uma interação com essas células e favorecem o fotoenvelhecimento ${ }^{5}$.

$\mathrm{O}$ aumento da preocupação da população com a saúde e com o processo de envelhecimento cutâneo fomentou o desenvolvimento de tecnologias e/ou aperfeiçoamentos de técnicas capazes de promover o rejuvenescimento ${ }^{6}$. Atualmente, existe uma série de recursos terapêuticos não invasivos capazes de manter a boa conformação tecidual a fim de controlar o envelhecimento cutâneo, como tratamentos tópicos e aplicação de $\operatorname{cosméticos}^{7}$. Além desses recursos, destaca-se o uso da eletroterapia com laser não ablativo, a radiofrequência e técnicas como indução percutânea de colágeno, comumente conhecida como microagulhamento ${ }^{6,8,9}$.

Um novo recurso terapêutico vem sendo usado com o objetivo de promover o rejuvenescimento através da diminuição de rugas e linhas de expressão. Trata-se do jato de plasma ${ }^{10}$. Este equipamento faz uso do plasma, em elevados graus de temperatura, mediante uma descarga contínua de corrente elétrica, que promove calor no tecido cutâneo. A aplicação da técnica estimula o tecido a elevar os índices de produção de colágeno, além de acarretar em uma retração das fibras elásticas, fator que proporcionará melhora na qualidade do tecido ${ }^{11}$.

Um dos recursos diagnósticos capaz de avaliar e quantificar o efeito do jato de plasma sobre o tecido é o exame de termografia infravermelha ${ }^{12}$. Trata-se de um equipamento de imagem que possibilita a análise de variação térmica do tecido. Este instrumento é uma câmera que possui detectores infravermelhos de análise que capturam imagens. A radiação infravermelha e a distribuição térmica corporal serão evidenciadas. Desta forma, é possível avaliar se existe um aumento da temperatura na superfície cutânea. A variação térmica pode estar relacionada com fatores circulatórios e sofrer alterações devido às variações de fluxo e volume sanguíneo ${ }^{13,14}$.

Diante do exposto, este estudo objetivou relatar uma série de casos clínicos e avaliar a acurácia da termografia infravermelha em evidenciar os efeitos do jato de plasma no padrão de variação térmica do tecido cutâneo de pacientes do sexo feminino que apresentavam rugas faciais.

\section{METODOLOGIA}

\section{Aprovação no Comitê de Ética}

Este estudo foi submetido ao Comitê de Ética em Pesquisa em seres humanos da Escola Bahiana de Medicina e Saúde Pública e seguiu todas as diretrizes e normas estabelecidas na Resolução 466/2012. O número do parecer de aprovação pelo CEP foi 4.217.415.

\section{Amostra}

Tratou-se de um estudo descritivo, de caráter exploratório, do tipo série de casos clínicos. Foi utilizada uma amostra de conveniência, composta por 5 mulheres provenientes de uma clínica de Fisioterapia Dermatofuncional privada, através de livre demanda. Como critérios de inclusão, foram consideradas elegíveis pacientes com idade acima de 40 anos, apresentando rugas faciais com classificação tipo III e IV, de acordo com a Escala de Glogau adaptada para avaliação dos aspectos estéticos da pele ${ }^{15}$ e que tinham disposição para participar da pesquisa através de assinatura de TCLE. Foram excluídas da pesquisa mulheres que possuíam alguma contra-indicação para receber a terapia do jato de plasma, a exemplo do uso de marca-passo, gestantes, epilépticas, que possuíssem implantes de metal na área tratada, tivessem fototipos cutâneos altos, acima de IV, ou apresentassem algum tipo de lesão no local da aplicação.

\section{Utilização do Recurso Eletroterapêutico}

O procedimento consistiu na utilização de jato de plasma para o tratamento de rugas faciais localizadas na região supraorbitária, em sessão única. Inicialmente, as pacientes foram submetidas a uma rigorosa anamnese a fim de documentar a história clínica, bem como transmitir todas as informações a respeito do tratamento e as devidas recomendações que deveriam ser adotadas antes da sua realização. Entre estas, destacou-se a necessidade de se absterem do uso de bebidas alcoólicas, não realizar atividades físicas e não fumar nas últimas três horas que antecediam ao tratamento.

Após exame físico as pacientes foram conduzidas individualmente a uma sala reservada, onde foi realizado o primeiro registro termográfico. Em seguida, seus rostos foram higienizados com gel de limpeza purificante da ADCOS (VITCOS - Comércio de Cosméticos LTDA, Vila Velha, Espírito Santo, Brasil). Logo após a higienização da face, foi aplicada uma pomada anestésica tópica (Dermomax, São Paulo, Brasil), com lidocaína a $4 \%$. As pacientes aguardaram em uma sala de espera, por 30 minutos, até o anestésico fazer efeito. A posteriori, foram levadas novamente à sala de procedimento. As pacientes foram orientadas a deitar em decúbito dorsal na maca, para que fosse removido todo e qualquer resíduo de pomada anestésica. Nesse momento foi realizado o segundo termograma. Em seguida, as pacientes foram submetidas ao tratamento com o jato de plasma, finalizando o procedimento com o ultimo registro termográfico, imediatamente após o fim da terapia. Por fim, as pacientes receberam orientações quanto aos cuidados pós-terapêuticos a fim de evitar quaisquer efeitos adversos.

O aparelho utilizado foi o Jett Plasma Lift (Celebrim Importações e Distribuições LTDA, São Paulo, Brasil) composto por quatro aplicadores e eletrodos de espuma, responsáveis por fechar o campo magnético. 0 disposi- 
tivo gera uma descarga de faísca e plasma usando uma corrente de $5 \mathrm{Kv}, 1 \mathrm{~mA}$. A tensão do gerador de descarga de plasma pode variar de 0,8 a $7 \mathrm{kV}$ e a intensidade, de 0,3 a 1,8 W. Ocorre um desligamento automático de alta voltagem após os primeiros 20 segundos da aplicação e uma diminuição acelerada da tensão na ponta a zero após 1 segundo. A intensidade usada foi 8/8. Utilizou-se do aplicador em cone, para a realização da fulguração. Este método consiste em fazer pontilhamentos perpendiculares as linhas de expressão. 0 tempo médio de duração do procedimento foi de 15 minutos. $O$ sítio anatômico tratado com o jato de plasma compreendeu toda e somente à região supra orbital com percurso linear até a linha média, de forma ascendente em direção ao couro cabeludo, de ambos os lados, em todas as pacientes, com uma área média de abrangência da ordem de $18 \mathrm{~cm}$.

\section{Análise Termográfica}

Para avaliação do coeficiente de variação térmica local foi utilizada uma câmera infravermelha da marca FLIR Série-E (Victoria, Suécia) com 320×240 pixels de resolução e frequência de imagem de $60 \mathrm{~Hz}$ que captura imagens em tempo real e conectividade Wi-Fi (E60). O equipamento realiza estudos na faixa de temperatura de $-20^{\circ} \mathrm{C}$ à $650^{\circ} \mathrm{C}$ e possui sensibilidade térmica (N.E.T.D.) maior que $0,05{ }^{\circ} \mathrm{C}$ e até $30{ }^{\circ} \mathrm{C}$. Atua na faixa espectral de ondas eletromagnéticas compreendida entre 7,5 a $13 \mu \mathrm{m}$, correspondendo a uma faixa de infravermelho distante. Para obter um padrão das imagens foi adotado o seguinte protocolo: a altura da câmera em relação ao solo e a distância desta em relação as pacientes serão de $1 \mathrm{~m}$. As pacientes foram posicionados em decúbito dorsal, na maca de procedimentos. A temperatura do ambiente não interferiu nos registros termográficos, pois esta se manteve controlada, em torno de $20^{\circ} \mathrm{C} \pm 1$ ${ }^{\circ} \mathrm{C}$, durante todos os procedimentos, a fim de garantir uma padronização nos termogramas. $\mathrm{O}$ range variou de 27 a 35 ㅇ $C$.

A avaliação termográfica não sofreu interferência proveniente da região da face a ser fotografada, visto que todas as pacientes receberam tratamento na mesma área, sendo esta a mesma na qual foi feito o registro termográfico. Além disso, o anestésico tópico não contribuiu para o aumento da temperatura local, pois o mesmo oferece um efeito vasoconstritor. Esta ação ocasiona uma redução no fluxo sanguíneo, com redução da temperatura ${ }^{16}$.

Os critérios de normalidade e anormalidade adotados nessa pesquisa foram baseados no estudo de Haddad et al. ${ }^{17}$. Neste estudo foi estabelecido um padrão de alteração na normalidade, para determinar se houve ou não alteração significativa de temperatura na região tratada, descrita na TABELA 1.
Tabela 1 - Anormalidades clínicas de acordo com a variação de temperatura.

\begin{tabular}{ll}
\hline Variação térmica & Padrão de anormalidade \\
\hline$<0,4^{\circ} \mathrm{C}$ & Fraca \\
$>0,4^{\circ} \mathrm{Ce}<0,7^{\circ} \mathrm{C}$ & Moderada \\
$>0,7^{\circ} \mathrm{C}$ & Forte \\
\hline
\end{tabular}

Fonte: Dados da pesquisa

A avaliação termográfica não oferece riscos à saúde física das pacientes em avaliação, pois se trata de um exame de diagnóstico não invasivo e indolor ${ }^{18}$.

\section{Analise Estatística}

Foi criado um banco de dados no Microsoft ${ }^{\oplus}$ Excel $^{\circledR} 2010$ (versão 14.0.7132.5000), Microsoft ${ }^{\circledR}$ Office Professional Plus 2010, USA e analisado no software $R$ (versão 3.1.1). Foi realizada estatística descritiva e estabelecidas as variações do coeficiente térmico $(\Delta \mathrm{T})$ para as 5 pacientes analisadas. As alterações termográficas para cada período de documentação estabelecido foram consideradas significativas quando o $\Delta T$ foi superior a 0,4 oC, de acordo com critérios delineados ${ }^{17}$.

\section{RESULTADOS}

O gráfico 1 ilustra os valores de temperatura das pacientes em diferentes momentos. Observou-se que houve uma variação no coeficiente de temperatura da região supra orbital, local onde foi aplicado o anestésico e, após a espera de 30 minutos, a aplicação do jato de plasma. Foi possível perceber que, após a aplicação do anestésico tópico, as pacientes apresentaram uma queda na temperatura local superior a $2{ }^{\circ} \mathrm{C}$, possivelmente devido a um efeito vasoconstritor, capaz de ocasionar um analgesia dérmica proveniente do acúmulo do anestésico nas terminações nervosas e receptores da dor ${ }^{16}$. Porém, posteriormente à terapia com o jato de plasma, ocorreu novamente uma alteração na temperatura da região tratada. Todas as pacientes obtiveram um aumento de temperatura superior a $2,4{ }^{\circ} \mathrm{C}$, alcançando um valor de temperatura por vezes maior que a temperatura basal.

\section{Variação de temperatura da paciente 1}

R.K.A.C, 59 anos, Glogau tipo IV, apresentou temperatura inicial de $34,5{ }^{\circ} \mathrm{C}$ antes do início dos procedimentos. Após a aplicação do anestésico tópico, houve uma redução da temperatura local da ordem de $2,7^{\circ} \mathrm{C}$ (Temp $=31,8^{\circ} \mathrm{C} ; \Delta \mathrm{T}=-2,7^{\circ} \mathrm{C}$ ). Com a utilização do jato de plasma, houve um aumento significativo da temperatura (Temp $=34,3^{\circ} \mathrm{C} ; \Delta \mathrm{T}=+2,5^{\circ} \mathrm{C}$ ). Ao se comparar o efeito térmico induzido pelo jato de plasma à temperatura inicial, observou-se redução da temperatura em $0,2{ }^{\circ} \mathrm{C}$ (Temp = 34, $3^{\circ} \mathrm{C} ; \Delta \mathrm{T}=-0,2^{\circ} \mathrm{C}$ ); (Figura 1 ). 
Figura 1 - Termogramas da paciente 1, que exibem a temperatura máxima, média e mínima, pré anestésico; pósanestésico e após a terapia com jato de plasma.

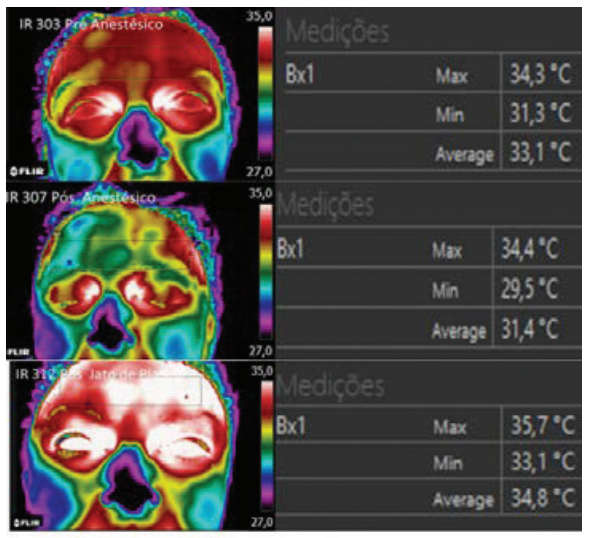

Fonte: autoria própria

\section{Variação de temperatura da paciente 2}

I.A.S, 58 anos, Glogau tipo IV, apresentou temperatura inicial média de $34,3^{\circ} \mathrm{C}$ antes do início do tratamento. Após a aplicação do anestésico tópico, houve uma redução da temperatura local da ordem de $2,8^{\circ} \mathrm{C}$ (Temp = $31,5^{\circ} \mathrm{C} ; \Delta \mathrm{T}=-2,8^{\circ} \mathrm{C}$ ). Com a utilização do jato de plasma, houve um aumento significativo da temperatura (Temp $=34,7^{\circ} \mathrm{C} ; \Delta \mathrm{T}=+3,2^{\circ} \mathrm{C}$ ). Ao se comparar o efeito térmico induzido pelo jato de plasma à temperatura inicial, observou-se que a temperatura permaneceu elevada $\left(\right.$ Temp $\left.=34,7^{\circ} \mathrm{C} ; \Delta \mathrm{T}=+0,4^{\circ} \mathrm{C}\right)$; (Figura 2).

Figura 2- Termogramas da paciente 2, que exibem a temperatura máxima, média e mínima, pré anestésico; pósanestésico e após a terapia com jato de plasma.

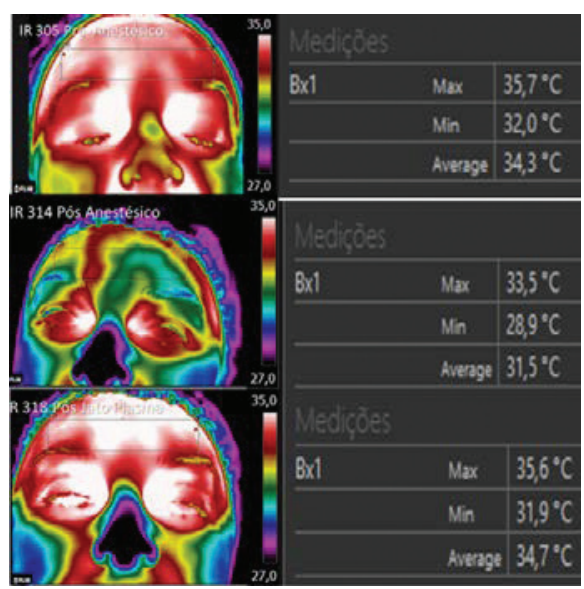

Fonte: autoria própria

Variação de temperatura da paciente 3

M.A.G.S, 65 anos, Glogau tipo IV, apresentou temperatura inicial média de $34,5{ }^{\circ} \mathrm{C}$ antes do início do tratamento. Após a aplicação do anestésico tópico, houve uma redução da temperatura local da ordem de $2,7^{\circ} \mathrm{C}$ $\left(\right.$ Temp $\left.=31,8^{\circ} \mathrm{C} ; \Delta \mathrm{T}=-2,7^{\circ} \mathrm{C}\right)$. Com a utilização do jato de plasma, houve um aumento significativo da temperatura ( Temp $=34,3^{\circ} \mathrm{C} ; \Delta \mathrm{T}=+2,5^{\circ} \mathrm{C}$ ). Ao se comparar o efeito térmico induzido pelo jato de plasma à temperatura inicial, observou-se redução da temperatura em $0,2{ }^{\circ} \mathrm{C}$ $\left(\right.$ Temp $\left.=34,3{ }^{\circ} \mathrm{C} ; \Delta \mathrm{T}=-0,2{ }^{\circ} \mathrm{C}\right)$; (Figura 3 ).

Figura 3- Termogramas da paciente 3, que exibem a temperatura máxima, média e mínima, pré anestésico; pósanestésico e após a terapia com jato de plasma.

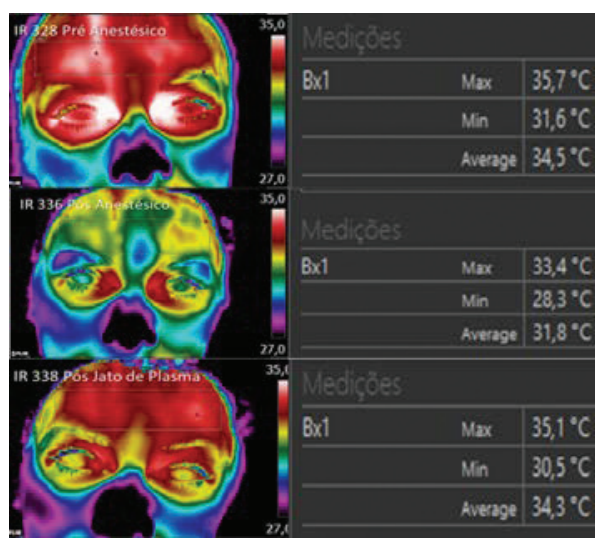

Fonte: autoria própria

\section{Variação de temperatura da paciente 4}

N.A.S, 47 anos, Glogau tipo III, apresentou temperatura inicial média de $33,6{ }^{\circ} \mathrm{C}$ antes do início do tratamento. Após a aplicação do anestésico tópico, houve uma redução da temperatura local da ordem de $2,3{ }^{\circ} \mathrm{C}$ $\left(\right.$ Temp $\left.=31,3^{\circ} \mathrm{C} ; \Delta \mathrm{T}=-2,3^{\circ} \mathrm{C}\right)$. Com a utilização do jato de plasma, houve um aumento significativo da temperatura (Temp $=36,0^{\circ} \mathrm{C} ; \Delta \mathrm{T}=+4,7^{\circ} \mathrm{C}$ ). Ao se comparar o efeito térmico induzido pelo jato de plasma à temperatura inicial, observou-se que a temperatura permaneceu elevada (Temp $\left.=36,0{ }^{\circ} \mathrm{C} ; \Delta \mathrm{T}=+2,4^{\circ} \mathrm{C}\right)$; (Figura 4)

Figura 4- Termogramas da paciente 4, que exibem a temperatura máxima, média e mínima, pré anestésico; pósanestésico e após a terapia com jato de plasma.

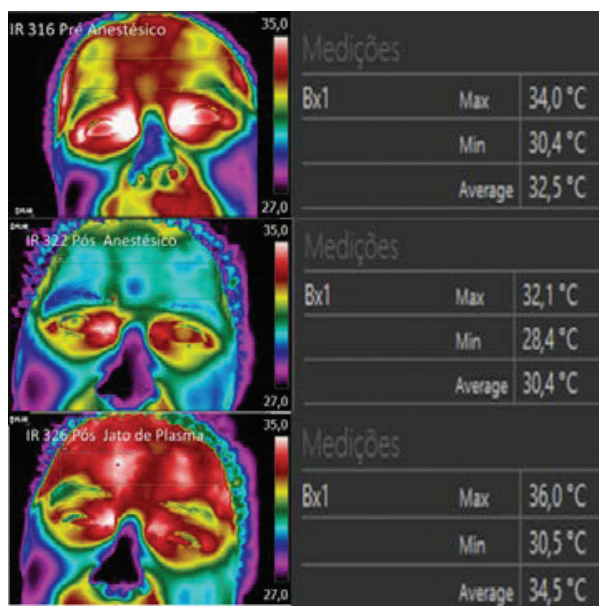

Fonte: autoria própria 


\section{Variação de temperatura da paciente 5}

G.S.S.P, 42 anos, Glogau tipo III, apresentou temperatura inicial média de $32,5^{\circ} \mathrm{C}$ antes dos procedimentos. Após a aplicação do anestésico tópico, houve uma redução da temperatura local da ordem de $2,1{ }^{\circ} \mathrm{C}($ Temp $=$ $30,4^{\circ} \mathrm{C} ; \Delta \mathrm{T}=-2,1^{\circ} \mathrm{C}$ ). Com a utilização do jato de plasma, houve um aumento significativo da temperatura (Temp $=34,5^{\circ} \mathrm{C} ; \Delta \mathrm{T}=+4,1^{\circ} \mathrm{C}$ ). Ao se comparar o efeito térmico induzido pelo jato de plasma à temperatura inicial, observou-se que a temperatura permaneceu elevada $\left(\right.$ Temp $=34,5^{\circ} \mathrm{C} ; \Delta \mathrm{T}=+2,0^{\circ} \mathrm{C}$ ); (Figura 5).

Figura 5- Termogramas da paciente 5, que exibem a temperatura máxima, média e mínima, pré anestésico; pósanestésico e após a terapia com jato de plasma.

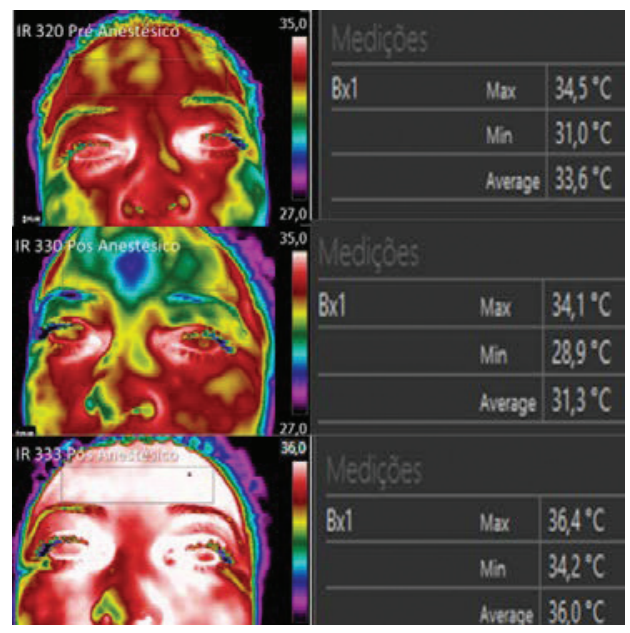

Fonte: autoria própria

Gráfico 1- Variação do coeficiente térmico das pacientes tratadas com jato de plasma temperatura inicial, pósanestésico e pós terapia.

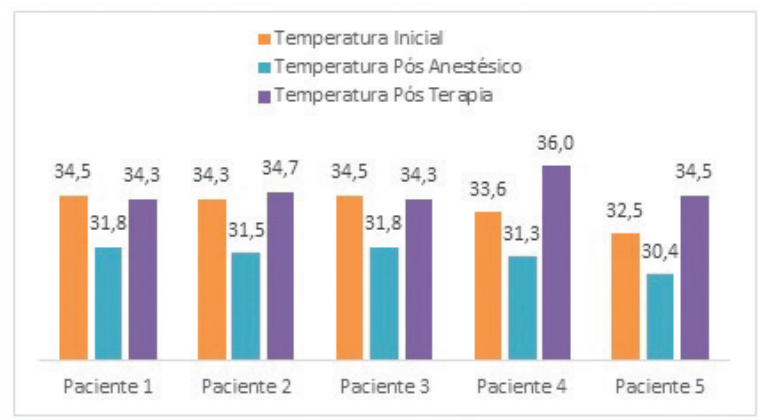

Fonte: autoria própria

\section{DISCUSSÃO}

A pele é considerada o maior órgão do corpo. É responsável pelo recobrimento de toda a superfície corporal. Protege o tecido gorduroso, fáscias, músculos e ossos. Desempenha um importante papel funcional, devido à grande diversidade de células presentes em seus estratos. Realiza funções indispensáveis para o bom funcionamento do organismo, dentre elas regulação térmica, sensorial, do fluxo sanguíneo e de defesa ${ }^{9,19}$.

Uma vez que o tecido cutâneo apresente alterações funcionais e morfológicas significativas, sofrerá modificações na epiderme e na derme, como por exemplo, aquelas observadas no tecido conjuntivo que terá a sua capacidade de absorção de oxigênio e de nutrientes reduzida. Tal fato pode provocar uma desidratação significativa na pele e acarretar o surgimento de rugas, redução da elasticidade e perda da tensão do tecido cutâneo ${ }^{20,21}$.

Com o objetivo de atender à forte demanda da população que apresenta alguma insatisfação no que se refere às características estéticas, principalmente na região de face, mais precisamente rugas e linhas de expressão, ocorreram inúmeros avanços tecnológicos na eletroterapia estética. Tais avanços possibilitaram aos profissionais, da área de Fisioterapia Dermatofuncional, desenvolverem diferentes tipos de tratamento e recursos terapêuticos para corresponder às necessidades do mercado 6 .

Atualmente, existe uma série de recursos terapêuticos não invasivos capazes de manter a boa conformação tecidual a fim de controlar o envelhecimento cutâneo, como tratamentos tópicos e aplicação de cosméticos. Além desses recursos, destaca-se o uso de inúmeros equipamentos disponíveis na eletroterapia avançada com a finalidade de tratar inúmeras disfunções estéticas da face, como as rugas, que são decorrentes do processo natural de envelhecimento, bem como a associação deste com agentes externos. Neste sentido, pode-se citar o uso do laser não ablativo, a radiofrequência e técnicas como indução percutânea de colágeno, comumente conhecimento como microagulhamento ${ }^{7}$.

O laser não ablativo é um recurso terapêutico que utiliza energia eletromagnética para retardar o processo de envelhecimento cutâneo. Esse dispositivo tem ganhado bastante visibilidade no mercado dermatológico pois é capaz de promover elevado grau de remodelação da matriz colagênica, através da sua capacidade de gerar calor na derme, sem afetar a epiderme. Desta forma, melhora a qualidade do tecido cutâneo e minimiza os sinais de fotoenvelhecimento da pele ${ }^{6}$. A radiofrequência é capaz de promover uma vasodilatação no local de aplicação, através do aumento da temperatura gerada pelo aparelho. O crescente fluxo sanguíneo acarretará na chegada de oxigênio e nutrientes. Além disso, o aumento da temperatura irá proporcionar a contração das fibras de colágeno existentes, bem como a neocolagênese derivada dos estímulos de ativação das células sintetizadoras de colágeno, os fibroblastos. Desta forma, essa técnica também pode favorecer na redução das rugas faciais ${ }^{8}$.

O microagulhamento, também conhecido como terapia de indução de colágeno, tem como principal objetivo gerar pequenas injúrias de natureza física no 
tecido cutâneo, de modo a estimular um aumento na produção de colágeno no local, devido ao processo fisiológico de reparo tecidual que ocorrerá no microambiente da lesão. A técnica também é capaz de promover uma melhor absorção de ativos no tecido, visto que uma vez microagulhada, a permeação de dermocosméticos será potencializada. Este recurso tem apresentado resultados significativos no tratamento de rugas e sinais de enveIhecimento ${ }^{22}$. Nesse cenário, o jato de plasma também tem sido utilizado com o objetivo de tratar alterações cutâneas provenientes do envelhecimento tecidual, sendo capaz de estimular o aumento na produção de colágeno. Quando este gás ionizado atinge a superfície da pele, ele é capaz de produzir uma espécie de dano térmico que estimula a produção de colágeno além de promover uma reestruturação no padrão organizacional das fibras elásticas ${ }^{23}$.

O plasma, na física, é considerado como o quarto estado da matéria. Trata-se de um gás com alto teor de energia. Este termo vem do grego e significa "algo moldado". Foi descrito pelo físico-químico norte-americano Irving Langmuir, em 1928, como a combinação diversa de constituintes de gases com elevado índice de ionização, semelhantes ao plasma sanguíneo ${ }^{11}$. Seu uso já vem sendo descrito na literatura há muitos anos, devido à sua utilização no processo de esterilização de diversos materiais como equipamentos médicos e embalagens de alimentos ${ }^{24}$.

Diversos estudos apontam a aplicabilidade do plasma em baixas temperaturas com o objetivo de acelerar o processo de cicatrização de feridas devido a sua capacidade de reduzir a carga bacteriana no local tratado ${ }^{25,26}$. Este recurso terapêutico é capaz de gerar um aumento na concentração de óxido nítrico (NO) no tecido, este componente por sua vez, é um potente vasodilatador. A vasodilatação permite uma aceleração nas etapas do processo de cicatrização, pois através dela, o transporte das células de defesa será facilitado assim como a difusão de nutrientes e oxigênio. Todos estes são essenciais para viabilizar o processo de reparo tecidual ${ }^{27,28}$.

Apesar de pouco difundido na literatura, o jato de plasma já vem sendo bastante usado por profissionais da área da saúde, com o objetivo de promover rejuvenescimento, através da diminuição de aspectos inestéticos provenientes do processo de envelhecimento cutâneo ${ }^{29}$. Nesta finalidade, faz-se o uso do plasma quente, que através de uma descarga de corrente contínua, é capaz de liberar energia na forma de calor, esta será canalizada até o alvo e perceptível no tecido ${ }^{10}$. A aplicação do jato de plasma acarretará em estímulos no tecido que induzirão um aumento na produção de colágeno e redução de fibras elásticas de modo a melhorar a qualidade e reestruturar este tecido, que sofreu danos térmicos provenientes da indução controlada de calor, gerada pela aplicação do equipamento ${ }^{11}$.

No presente estudo, a análise comparativa dos termogramas pré e pós terapia com o jato de plasma, demonstraram o aumento da temperatura na área tratada em todas as pacientes. Esta variação no termograma sugere que o recurso eletroterapêutico foi capaz de gerar um aumento na microcirculação local devido à liberação da energia, gerada pelo gás excitado, que forma o plasma, pois este é capaz de promover um aquecimento rápido da pele ${ }^{30}$. Ademais, sabe-se que a indução de uma lesão térmica no tecido pode gerar alterações nos padrões tissulares, devido a ocorrência de uma vasodilatação e da abertura de capilares, seguida de uma neovascularização e neocolanogênese ${ }^{31,32}$.

Embora este estudo abranja uma série de casos clínicos e, portanto, apresente limitações, pode-se observar que a termografia foi eficaz para evidenciar as alterações de temperatura pós terapia com o jato de plasma. Todas as pacientes apresentaram Delta $T$ positivo, com aumento dos valores de temperatura, sendo capazes de reverter a diminuição da temperatura provocada pelo efeito vasoconstritor do anestésico tópico. Tal fato foi importante para fins de comprovação da ação do jato de plasma no que se refere a elevação da temperatura local, sugerindo incremento da microcirculação da área submetida à terapia. De fato, a técnica de fulguração tem sido descrita na literatura como capaz de gerar uma desnaturação nas células, porém as mesmas permanecem viáveis, ou seja, não há uma destruição na atividade biológica da molécula ${ }^{30,31}$. A realização de estudos prospectivos com maior número de pacientes experimentais, que possam documentar a ação in loco do jato de plasma na pele, torna-se fundamental para ampliar a compreensão dos efeitos induzidos por esta modalidade terapêutica, visto que, trata-se de uma técnica pouco disseminada na literatura.

No presente estudo, foi observado que três pacientes exibiram temperatura final superior à inicial documentada. Este fato pode sugerir que a lesão térmica induzida pelo jato de plasma foi mais intensa. Outra possível explicação para este fato pode estar relacionada à interferência da variabilidade individual na resposta à terapia proposta. A lesão térmica induzida pelo jato de plasma tem sido caracterizada por estimular uma intensa atividade fibroblástica após a realização da terapia, que resulta no aumento da biossíntese de um novo colágeno e de fibras de elastina, e desta forma, contribui para amenizar rugas e linhas de expressão na área tratada ${ }^{30}$.

A análise termográfica é uma ferramenta diagnósti$\mathrm{ca}$, de imagem, não invasiva, indolor, realizada de forma rápida, com um baixo custo e que não oferece risco ao paciente, pois não envolve radiação ionizante. Esse recurso é capaz de evidenciar a atividade vasomotora do tecido cutâneo. A formação de imagem é possível através da captação e transformação da distribuição térmica corporal, sendo capaz de captar se há um aumento da microcirculação local, através do aumento de temperatura ${ }^{13,17}$.

A presente pesquisa sugere que o uso da termografia como ferramenta de monitoramento do padrão 
microcirculatório, foi eficiente para analisar quali e quantitativamente, de forma não invasiva e indolor, o local submetido à terapia com jato de plasma. Através da utilização deste recurso imaginológico de diagnóstico foi possível comprovar a ação do jato de plasma no tecido cutâneo tratado com a finalidade terapêutica de promover rejuvenescimento e redução das rugas e linhas de expressão através do aumento da circulação e do aporte sanguíneo local e possível estímulo à biossíntese de colágeno que precisaria ser comprovada através de um estudo anatomopatológico do tecido em questão.

Como uma possível limitação deste estudo, pode-se citar o pequeno número de pacientes que participaram dos registros termográficos. Faz-se necessário documentar os termogramas de um número maior de pacientes, em períodos de análise mais amplos que nos permitam avaliar não só o efeito imediato da terapia com jato de plasma, mas também aqueles a longo prazo.

\section{CONCLUSÃO}

Este estudo evidenciou a acurácia da termografia infravermelha em detectar o incremento da microcirculação induzido pelo uso do jato de plasma aplicado na região supra orbitária. $O$ jato de plasma foi capaz de reverter a diminuição da temperatura provocada pelo uso do anestésico tópico, e esta ação foi refletida pela variação ascendente do coeficiente térmico da área tratada. Desta forma, pode-se sugerir que a variação térmica foi resultante do processo de vasodilatação e abertura de esfíncteres de novos capilares sanguíneos. Os autores encorajam a realização de mais estudos que contemplem as possíveis alterações fisiopatológicas decorrentes da utilização do jato de plasma, pois este recurso terapêutico pode ser utilizado por diversos profissionais da área da saúde, a exemplo de médicos, fisioterapeutas, enfermeiros e biomédicos, desde que estejam habilitados e capacitados para realizar a técnica.

\section{REFERÊNCIAS}

1. CIOSAK, S, I. et al. Senescência e senilidade: novo paradigma na atenção básica de saúde. Rev. Esc. Enferm. USP, São Paulo, v. 45, p. 1763-1768, 2011.

2. PEREIRA, S. Dermatoses no idoso. In: ROTTA, O. Guia de dermatologia: clínica, cirúrgica e cosmiátrica. São Paulo: Manole, 2008. p. 567, n. 91.

3. BARROS, C. M.; BOCK, P. M. Vitamina C na prevenção do enveIhecimento cutâneo. 2012. Disponível em: http://www.crn2.org.br/ pdf/artigos1277237393.pdf. Acesso em: 11 jul. 2012.

4. MONTAGNER, S.; COSTA, A. Bases biomoleculares do fotoenvelhecimento. An. Bras. Dermatol., Rio de Janeiro, v. 84, n. 3, p. 263-269, 2009.

5. FREITAS, P. et. al. Tratado de geriatria e gerontologia. 12. ed. São Paulo: Guanabara Koogan, 2006.

6. CAMPOS, V. B. et al. Estudo comparativo do laser fracionado não ablativo $1340 \mathrm{~nm}$ para rejuvenescimento facial: alta energia com pas- sagem única versus energia média e passagem tripla. Surg. Cosmet. Dermatol., Jordão. v. 9, n. 3, p. 228-236. 2017.

7. FOOLAD, N. et al. Prospective randomized controlled pilot study on the effects of almond consumption on skin lipids and wrinkles. Los Angeles: Phytotherapy Research, 2019. p. 1-6.

8. SILVA, R. M. V. et al. Efeitos da radiofrequência no rejuvenescimento facial: estudo experimental. ConScientiae Saúde, Natal, v. 16, n. 2, p. 194-200, 2017.

9. BORGES, F, S.; SCORZA, F, A. Terapêuticas aplicadas a estética: conceitos e técnicas. São Paulo: Ed Phorte. 2016. p. 10-17.

10. FOSTER, K. W.; MOY, R. L.; FINCHER, E. F. Advances in plasma skin regeneration. J. Cosmet. Dermatol., Los Angeles, n. 7. p. 169-179, 2008.

11. HEINLIN, J. et al. Medicina Plasma: possíveis aplicações em dermatologia. Berlim: Jornal @ Blackwell Verlag GmbH, 2010. p. 1610-0379.

12. CORTE, A. C. R.; HERNANDEZ, A, J. Termografia médica infravermelha aplicada à medicina do esporte. Rev. Bras. Med. Esporte, São Paulo, v. 22, n. 4, jul./ago. 2016.

13. ANDRADE FILHO, A. C. de. C. Termografia no diagnóstico das dores músculo-esqueléticas. São Paulo, 2008. Cap. 15.

14. ALFIERI, F. M.; SANTOS, A. C. A.; BATTISTELLA, L. R. Uso da termografia como método de avaliação na medicina física e de reabilitação. Acta Fisiatr., São Paulo, p. 147-150, 2007.

15. SOVINSKI, S. R. P. et al. Avaliação estética da face em indivíduos com deformidades dentofaciais. Rev. CEFAC, São Paulo, v. 18, n. 6, p. 1348-1358, nov./dez. 2016.

16. FLORES, M. P.; CASTRO, A. P. C. R.; NASCIMENTO, J. S. Analgésicos tópicos. Rev. Bras. Anestesiol., Rio de Janeiro, v. 62, n. 2, p. 244-252, 2012.

17. HADDAD, D. S. et al. A new evaluation of heat distribution on facial skin surface by infrared thermography. Londres: British Institute of Radiology, 2016.

18. FITZGERALD, A.; BERENTSON-SHAW, J. Themography as a screening and diagnostic tool: a systematic review. New Zealand: JNZMA, 2012.

19. SCHNEIDER, L. V. Estrutura da pele e seus anexos. Curso Extensivo de Cosmetologia. Porto Alegre, v. 1, n. 5, p. 2-13. 2000.

20. OLIVEIRA, E, C. et al. Uso da micropuntura no tratamento de rugas. Fisioter. Bras., Rio de Janeiro, v. 18, n. 4, p. 481-488, 2017.

21. ARANGO, A. C.; MUNOZ, S. V.; SANCLEMENTE, G. Mechanisms of skin aging. latreia. Medelim, v. 30, n. 2. p. 160-170, Apr./June 2017.

22. LIMA, A. A.; SOUZA, T. H.; GRIGNOLI, L. C. E. Os benefícios do microagulhamento no tratamento das disfunções estéticas. Revista Científica da FHO, São Paulo, v. 3, n. 1, 2015.

23. CHANG, Y. T.; CHEN, G. Oral bacterial inactivation using a novel lowtemperature atmospheric-pressure plasma device. J. Dent. Sci., [s.l], v.11, n.1, p. 65-71, Mar. 2016.

24. KONG, M. G. et al. Plasma medicine: an introductory review. New Journal of Physics, Germany, n. 11. 2009.

25. ISBARY, L. et al. Um primeiro ensaio controlado randomizado potencial para diminuir a carga bacteriana utilizando árgon atmosférico frio plasma em feridas crónicas em pacientes. J. Dermatol., Mumbai, 5 mar. 2010. 
26. FRIDMAN, G. et al. Comparison of direct and indirect effects of non-thermal atmospheric-pressure plasma on bacteria. Alemanha: Weinheim, 2007.

27. WELTMANN, E. et al. Atmospheric pressure plasma jet for medical therapy: plasma parameters and risk estimation. Plasma Phys., Germanyv, v. 49, n. 9, p. 631-640, 2009.

28. DAESCHLEIN, L.; DARM, K.; NIGGEMEIER, M. A terapia para o tratamento de lesões necróticas purulenta e dos membros inferiores em pacientes diabéticos. Khirurgiia, 2004.

29. POTTER, M. J. et al. Facial acne and fine lines transforming patient outcomes with plasma skin regeneration. Ann. Plast. Surg., California, v. 58, n. 6. June 2007.

30. KILMER, S. et al. A pilot study on the use of a plasma skin regeneration device (Portrait ${ }^{\circledR}$ PSR) in full facial rejuvenation. London: Lasers in medical Science, 2007.

31. ROSA, R. S. Avaliação morfológica do colágeno após aquecimento induzido in vivo. 2007. 99f. Dissertação (Mestrado) - Escola de Engenharia de São Carlos, Faculdade de Medicina de Ribeirão Preto e Instituto de Química de São Carlos, Universidade de São Paulo, São Carlos, 2007.

32. PITELLA FILHO, B. G. et al. Bogliolo patologia. 5. ed. Rio de Janeiro: Guanabara Kooga, 1994.

Submetido em: 20/12/2020

Aceito em: 20/04/2021 